\title{
Understanding and Acting Upon a Creeping Crisis
}

Arjen Boin, Magnus Ekengren, and Mark Rhinard

Abstract The notion of a creeping crisis is a conceptual one, a heuristic device useful for helping to uncover hidden dimensions of today's more pressing — some might say existential-societal problems. In this introductory chapter, we present our definition of creeping crisis and unpack the analytical dimensions of the concept. We review what existing research does and does not tell us about those dimensions. The chapter concludes by highlighting key research questions and outlining how the case studies in the book help to answer those questions.

\footnotetext{
A. Boin $(\square)$

Department of Political Science, Leiden University, Leiden, The Netherlands e-mail: boin@fsw.leidenuniv.nl

M. Ekengren

Department of Security, Strategy and Leadership, Swedish Defence University, Stockholm, Sweden

e-mail: Magnus.Ekengren@fhs.se

M. Rhinard

Swedish Institute of International Affairs, Stockholm, Sweden

Stockholm University, Stockholm, Sweden

e-mail: mark.rhinard@ekohist.su.se

(C) The Author(s) 2021

A. Boin et al. (eds.), Understanding the Creeping Crisis, https://doi.org/10.1007/978-3-030-70692-0_1
} 
Keywords Creeping crises $\bullet$ Crisis management • Early warning • Crisis incubation $\bullet$ Crisis detection $\bullet$ Crisis response

\subsection{INTRODUCTION}

Modern societies are beset by a special species of trouble. We may know they exist, damage may be accumulating, and they may eventually become a full-blown crisis. But little is done to intervene or manage them. Authorities act insufficiently, or fail to act at all, essentially sleepwalking into greater troubles in the indeterminate future. We refer to these slowly emerging threats in terms of "creeping crises."

Creeping crises are telling characteristics of our time. The financial crisis in the U.S. was lurking behind success stories about a steaming-hot economy. Immigrants were reaching the borders of Europe in everincreasing numbers, but it took years before the immigration was recognized as a continental-wide crisis that could tear the European Union apart. The Covid-19 pandemic is just the most recent example of a creeping crisis that turned into a disaster.

Other potential crises simmer on the horizon. Climate change may well cause increasing number of forest fires and weather-related disasters. The undermining of public institutions and elections by foreign entities may or may not constitute a crisis for national governments. A long string of technical disturbances (cyber breakdowns, energy outages) may or may not be signals of impending infrastructural crises. The continuing depletion of eco-diversity may spell disaster.

Our goal in this book is to introduce and explore the utility of the creeping crisis concept. We aim neither to displace traditional crisis definitions nor to start a new field of inquiry. The concept of creeping crisis is an analytical device. With it, we can better characterize the key features of modern societal problems, some of which are addressed in existing literature but few of which are brought together in a single concept. It trains attention on some neglected aspects of crises research: incubation periods, precursor events, attention-action feedback, crisis ownership, and legitimacy declines. For societies increasingly faced with major policy challenges ranging from pandemics to migration, and from climate change to cyber threats, the creeping crisis notion helps to untangle key dynamics of growing problems - to help understand our world better, 
to drive new research, and to question the organization of crisis management at all levels of governance.

The chapters in this book offer a proof of concept: exploring diverse cases using the creeping crisis approach, extracting key insights, and outlining future research questions. In this introductory chapter, we first define the creeping crisis and consider the novelty of the term. We outline four key features of creeping crises and review what we know from existing literature in contrast to what we need to know with the help of this volume. We then consider the implications for practitioners before outlining the book's contents.

\subsection{Defining the Creeping Crisis}

Traditional definitions of crises emphasize their fast-burning nature ('t Hart \& Boin, 2001). The term "crisis," especially in the way it appears in popular culture, connotes something that surprises us. Crises explode on the scene but usually disappear into the history books after they have been brought under control. They are seen as a discrete event, an exceptional situation with a clear beginning and end. This matches the traditional definition of crisis as a widely recognized threat to shared societal values that requires an urgent response under conditions of deep uncertainty (Rosenthal, Charles, \& 't Hart, 1989).

A creeping crisis is akin, but not perfectly aligned, to the notion of a slow-burning crisis ('t Hart \& Boin, 2001). Creeping crises have a long incubation time and may keep simmering long after the "hot phase" is over. They do not have a clear beginning or end. What seems like the hot phase may only be a precursor to even hotter phases or a gradual cooling of the threat. The creeping crisis can remain undetected, or be widely acknowledged as an urgent problem that is nevertheless not fully addressed. These dynamics lead to the following working definition (cf. Boin, Ekengren, \& Rhinard, 2020):

A creeping crisis is a threat to widely shared societal values or life-sustaining systems that evolves over time and space, is foreshadowed by precursor events, subject to varying degrees of political and/or societal attention, and impartially or insufficiently addressed by authorities.

This definition emphasizes that threat and urgency are social constructions. Crisis is the label that observers attach to the shared sense among a 
group that something they value is under threat. This raises questions of when and how the perceptions of many individuals begin to converge. In traditional crises - an explosion, an invasion, an earthquake-there is initially little room for different interpretations. For creeping crises, the collective perception of a threat is the result of a social process that plays out over time. That process may be instantaneous, or it may take years. It allows for a wide variance of interpretations.

This definition also incorporates the (relatively) objective nature of crises. An objective definition views crisis as an empirical phenomenon-a real threat - that has the potential to cause serious damage to critical values or systems. In this line of thinking, the development of threats attracts much interest. How problems originate and evolve, whether through natural systems, technical systems, or the socio-ecological-technical interface is the focus of study. If causes and development pathways are better understood, then perhaps points of intervention can be recognized and the crisis halted before it is too late.

Our creeping crisis approach brings together the objective and subjective perspectives. As we will see below, the subjective crisis definition emphasizes the importance of attention: if political elites, media, and the public do not collectively share a sense of crisis, it is hard to speak of a crisis in this perspective. The objective definition emphasizes the importance of accumulation of threat potential. In this objective perspective, a crisis is best understood as a developmental process with root causes, an incubation phase, an acute phase, and an aftermath.

What sets the creeping crisis apart from other types of undesirable events is the temporal and spatial dimension. Both the actual threat potential and attention develop over time and space. The "creeping" refers to the incremental, often slow speed of development when compared to other types of events. It can be described in terms of evolving disruptions that may be detectable but are hard to agree on. Such crises may evolve over space, too, owing to distant but interacting conditions not limited by geography or other limits. Their manifestations may pop up anywhere in the world, not least because of the interconnected nature of modern society. The pace and place complexity of creeping crises raise challenging questions for both researchers and practitioners, which we discuss in the next section.

We see a relation with other concepts. The notion of "vulnerability" is useful, usually defined as a weak point in a system or society. Research on that topic, however, is wide, diverse, and primarily focused on prevention 
rather than the broader scope of development of vulnerabilities and political attention (McLaughlin \& Dietz, 2008). "Risk management" bears some affinities to our agenda, although risk management approaches tend to take a highly technical view on identifying and calculating probabilities of known-rather than unknown-future troubles. "Wicked" or "intractable" problems characterize persistent policy challenges that resist solutions (Rittel \& Webber, 1973; Schön \& Rein, 1994). While useful, the literature surrounding those terms assume converging social perspectives that the problem exists.

In short, our definition of creeping crisis shines analytical light on four interlinked dynamics:

- the emergence and gradual development of threat potential, owing to interacting conditions over time and space;

- the foreshadowing of the threat through precursor events;

- the shifting nature of threat attention, amongst societal groups and public officials;

- the partial or insufficient response to the threat.

\subsection{The Dynamics of Creeping Crises}

We now breakdown the four dynamics to understand what the literature does - and does not-already tell us about creeping crisis, and what this book helps to shed additional light on.

\subsubsection{Origins and Development of Creeping Crises}

A distinguishing feature of creeping crises is their often long and drawnout development. Many traditional crises, even "slow onset" crises (Seabrooke \& Tsingou, 2019), can be tracked back to a specific point of time and a linear escalation trajectory. Creeping crises evolve in time and space and may be the result of non-linear processes. While such features complicate analysis, they also offer hope that understanding these early dynamics will lead to intervention opportunities.

A socio-technical systems approach to understanding crises offers some starting insights (La Porte, 1975). Modern societies build life-giving systems that are complex to the point of inscrutability. Even for those who design and operate these systems, including financial derivative models, power grids, cyber infrastructures, and transportation networks, their 
functioning and vulnerabilities cannot always be clearly understood. The consequence of complexity is that small errors or glitches can develop into powerful threats. Yet operators and regulators are rarely aware of these "pathogens" (Turner, 1978), making their detection and abolition exceedingly difficult. In effect, the complexity of the system hides the breakdown from public and expert view, allowing it to grow and morph (Perrow, 1984). This basic description of complex systems leads to a crucial lesson: crises often are the result of an incubation process. The idea of incubation is, of course, temporal at heart.

The dynamics of onset and incubation are not confined to Turner's and Perrow's worlds of high-risk technology. The way we organize society and design essential infrastructures increases the likelihood of problems "simmering" for long periods of time. The design of a single currency in Europe contained the seeds of its possible breakdown (Jones, Kelemen, \& Meunier, 2016). Deviations that might have self-corrected under the right conditions (debt accumulation), built up over time and were then accelerated by interdependent developments (cross-border capital flows, poor oversight); some of these, as we examine more closely below, were eventually triggered into a full-blown crisis.

By introducing the concept of tight coupling, Perrow (1984) explained that many complex systems are interwoven with other systems. This means that a small incident or glitch may travel, invisibly and unnoted, from one system to the other. The incubation concept is thus enriched with the concept of escalation: time and tight coupling may lead to unnoticed accumulation and acceleration of a crisis.

Another helpful insight emerges from a complexity perspective (Buchanan, 2000; Scheffer, 2009; Taylor, 2001). Originating in the study of physical and biological systems, this perspective lays the foundation for understanding the characteristics of a complex system as emergent from micro-interactions within the system. Systems organize their own complexity, building up to a "tipping point" that brings a complex system to the edge of disaster. The idea of temporality is further enriched here by emphasizing the non-linearity of the incubation phase (Ansell \& Bartenberger, 2017). Crises incubate, develop, and escalate toward a tipping point - but the temporal dynamics can vary wildly during this process.

Finally, we gain analytical purchase on the spatial dimension by drawing on what can be termed "transboundary complexity." The deep integration of complex systems creates fertile soil for new types of mayhem, their development hidden by a level of complexity that renders small glitches 
from detection by unknowing policymakers. The question is then not where in a nation or policy sector a crisis originates, but where in the world. This creeping crisis follows transboundary trajectories that originate in distant lands or seemingly unrelated policy domains, creeping up in national domains where they eventually transform into a large-scale crisis. (We note that spatiality is relative, with some crises emerging and developing close to home.) This transboundary spatiality of crisis creates deep uncertainty with regard to causes, dynamics, potential solutions, and consequences.

Under such conditions, slight disruptions have the time and space to morph: to take on new characteristics, owing either to their transfer into new threats or to new vectors. The shift of an infectious disease from one limited to animals toward one transmittable to humans (a zoonosis) creates a new threat spectrum. Migrants moving north become exploited by criminal networks intent on making money to transport desperate individuals, often by life-threatening means. Health threats interact with religious practices and rapid travel to eventually ignite a measles outbreak in Brooklyn, New York.

We asked our authors to explore the essential dynamics behind the emergence and development of "their" particular crisis. We want to know why and how their crisis originated and developed, in time and space, and how it may have morphed into a new threat. We are open to the fact that not all creeping crises escalate. Some may stall or recede during incubation processes. Regardless, one intriguing and puzzling feature of creeping crises, compared to traditional crisis, is we know they exist. We can almost see them coming, not least because of the potential for "precursor events." It is to that question we now turn.

\subsubsection{Foreshadowing by Precursor Events}

What sets a creeping crisis apart in our perspective from a "full-blown" crisis is the lack of remedial action that allows a creeping crisis to build-up its damage potential. Crises may not only build-up: they may even travel and reveal themselves across time and space. We not only know they exist; we witness regular (and potentially dangerous) manifestations of a bigger problem: small earthquakes, in the case of oil exploration; privacy breaches, in the case of Big Data; forest fires, in the case of climate change; isolated illness, in the case of antimicrobial resistance; or drowning migrants, in the 
case of the migrant crisis. Experts sound alarms, activists rally around the problem, and yet a crisis response fails to materialize.

What are precursor events? From an objective perspective, the literature on socio-technological systems suggest precursor events are signals in complex systems-signals that may be difficult to detect in the first instance. Signs given off by the accumulating problem (the release of pent-up energy, using Turner's terminology) are concealed by the complexity of the system, by not knowing what to look for. Research on industrial crises suggests that certain features in the development of an organization or technology offer signs of trouble ahead: an unexpected decline in the normal trajectory of an economy, for instance, or anomalies in organizational processes (Shrivastava, Mitroff, Miller, \& Miglani, 1988).

The subjective element here concerns how these precursor events are framed and characterized. Are these events recognized as isolated, discrete events or part of a broader incubation process? This question touches upon the politics of crisis recognition and sense-making. The literature reminds us politicians may not want to intervene. Attention for a creeping crisis may, after all, suggest previous neglect. They might want to intervene but don't know how to solve these creeping crises. Or the costs may be too high. For political purposes, it may simply be beneficial to play a potential crisis up or down. Indeed, a society may be unwilling to address the problem because it relies on its source-the case chapters in this book illustrate the point.

Precursor events in a creeping crisis point us to two intriguing questions. First, what might constitute a tipping point in the process of crisis development and the progression of precursor events? A tipping point marks the transition between gradual development and sudden escalation. In theory, a crisis may have multiple tipping points. Presumably, a crisis may also have a final tipping point (after either a massive crisis emerges, of after which the crisis has spent all of its energy). We are not sure in the case of creeping crises.

A second question concerns the dynamics of feedback loops. Precursor events, as a key dynamic in creeping crises, offer an excellent laboratory for studying feedback loops: how do certain crisis constructions (or lack thereof) and remedial action interact, shaping the accumulation of the problem? We want to know whether these relations may display self-propelling features: this is the case when an escalation in crisis development spurs political attention, which, in turn, may fuel the crisis (through 
ill-fated interventions, for instance). We also want to know how such cycles terminate or screech into reverse. Especially after the creeping crisis has burst into view and political attention has peaked, it is intriguing to study how a "crisis in slow motion" wears out political attention spans, picking up speed again as societal and political stamina wane.

\subsubsection{Varying Attention}

Crises are often described as rare moments of convergence when almost everybody, however briefly, agrees on the importance of a certain event or development. The creeping crisis complicates this widely accepted idea of crisis as a point of convergence. It has the potential to trigger convergence, but it has not attracted sufficient levels of attention so that we can state with reasonable certainty that a society is gripped by this or that particular problem.

The creeping crisis shares certain characteristics with the problem that is neglected by politicians and policymakers. Political scientists have paid ample attention to the question why people-citizens, journalists, politicians-consider certain societal features problematic, even labeling them as threats or crises, when they ignore many other features and developments (which, objectively speaking, may carry much more damage potential than those on which attention is lavished). This question of attention is usually discussed in terms of "agendas." Policy agendas are said to have limited "carrying capacity" - meaning that they only can hold so many problems deserving attention (Baumgartner \& Jones, 1993; Kingdon, 1995). The attention of the public, the media, and the political arena is inherently limited and selective. In addition, this attention also tends to be short-lived: citizens, journalists, and politicians can only remain interested in a certain problem for so long (Downs, 1972).

Why do people focus their attention on one problem, ignoring others? Intriguingly, the characteristics of the problem at hand do not seem to matter much. People can worry about problems for which no evidence exists (UFOs come to mind). They can blissfully ignore problems for which mountains of data exist, suggesting that disaster is imminent. Politicians in liberal democracies may choose to ignore certain problems, especially those that stretch into a future that exceeds their term or those that require too steep of a sacrifice, such as climate change or Big Data accumulation. 
To understand attention foci and cycles, we must, therefore, return to creeping crises as social constructions. This reminds us of the idea that various actors may work hard to push certain social constructions-we speak of "frames" in this context-because a certain frame serves their interest. How growing problems are framed has a major role in the extent to which societal interests are mobilized to consider something a problem (Schattschneider, 1960) and the "entrepreneurs" behind those framing efforts who attempt to pursue their own interests. Here multiple literatures converge: crisis scholars speak of "crisis exploitation" (Boin, McConnell, \& 't Hart, 2008) while security scholars speak of "securitization"-an effort to draw an issue not only up the normal policy but also into the realm of extraordinary treatment (Buzan, Waever, \& de Wilde, 1998).

The process of problem framing is a social process that is political at heart. The process is influenced by societal paradigms and fashionsinfluential ways of viewing problems and their effects on society. It is influenced by public institutions, which typically prefer certain problems (Schattschneider, 1960) as well as the structuring effects of existing paradigms and public debates (Turner, 1978). Some threats may simply escape the imaginary capacity of policymakers and citizens alike (Smet, Lagadec, \& Leysen, 2012; cf. Boin, Brown, \& Richardson, 2019). As we see in the 2015 migration crisis case, the Swedish public debate did not allow for proper preparation of the crisis: arguments for strong preparation and response were seen by some as a sign of xenophobia.

A key characteristic of the creeping crisis is the absence of attention (whereas a crisis is defined by a high level of attention). The damage potential of a threat may grow, but it matters in this definition whether different segments of society label the growing threat as a crisis. There may be another tipping point, which marks the threshold that must be passed for the crisis to attract sufficient social and political attention so that it is experienced as a crisis. The tipping point is not necessarily a moment of eruption after which the crisis quickly fades - the creeping crisis may keep on creeping. Both the beginning and the ending of these creeping crises are blurry.

A creeping crisis perspective thus raises the question of when and how does the level of attention to the problem escalate? Creeping crises, by our definition, are largely recognized as problems and, even manifest themselves occasionally (see above) but little is done. The colloquial way to put this: when is "enough," enough? What requires societies to 
construct an issue as worthy of attention, resources, and sacrifice? This, again, directs attention to tipping points.

When studying creeping crises, we must distinguish between three kinds of attention: expert attention, media attention, and political attention. It is the relationship between these interests, and feedback loops, that deserve analysis. We asked the chapter authors in this volume to consider all three kinds of attention, and the extent to which one drives the other(s). We also asked them to consider-even if the short length of these case studies does not allow full exposition-what might explain lack of attention or certain kinds of attention at different points in the development of a crisis. We asked them to search for tipping points that may explain a rise in political attention and how that related to crisis development.

\subsubsection{Insufficient Responses}

Creeping crises pose a unique combination of managerial challenges. They confront policymakers with a complex problem that is not easily resolvable without the sustained attention of politicians. By the time political attention reaches a tipping point that enables concerted and urgent action, there is no longer just a complex problem to solve but a crisis to manage. Crisis management is hard enough for public managers (Boin, 't Hart, Stern, \& Sundelius, 2016), but these challenges are compounded by the slow onset of the crisis: media and citizens will demand to know why this long-coming crisis was not addressed earlier.

Creeping crises certainly place a premium on governments' ability to detect the onset of a crisis. After all, the origin and evolution of creeping crises are complicated. Traditional crisis detection, as the literature tells us, is already challenging. First, there are psychological factors that explain why people fail to recognize impending danger (Kahneman, 2013). It is hard to wrap your head around "unknown unknowns." If you cannot imagine a particular threat, you are unlikely to recognize it. Second, we know that most organizations find it hard or do not even try to detect crises. The challenge is not easy: it is hard to recognize creeping crises that manifest themselves in far-away locales.

Creeping crises pose yet another challenge (Boin \& Lodge, 2019). Due to their ambiguous character, the "ownership" of these crises tends to be ill defined. We know that defined, agreed-upon risks are monitored and addressed (through regulation, for instance) in the risk area. This area is 
dominated by professionals who are trained to minimize the chance that a known risk will materialize. When risks do unexpectedly materialize, their management is shifted to the crisis arena. Here trained crisis professionals try to organize an effective and timely response. The problem with creeping crises is that they qualify neither as an agreed-upon risk nor as a full-blown crisis. Without defined ownership, an organized response in the early phase is unlikely (Boin et al., 2020).

Another key challenge is the translation from ambiguous information to a strategic decision-making agenda. If you don't know, exactly, what is going on, what decisions should be made? In the absence of verified knowledge, a rational problem-solving approach cannot work. A crisis is, after all, political at heart ('t Hart, 1993; Boin et al., 2016).

Due to the highly ambiguous nature of creeping crises, we expect political motives to play an important role in the decision-making process. Research tells us that most politicians will seek to avoid the blame that may be assigned to them in the wake of a crisis (Boin et al., 2008; Hood, 2011). Their decision-making calculations are informed by the probability that they will be cast as the villain during the aftermath of a crisis. The outcome of this calculation will inform their willingness to take ownership of the creeping crisis.

We asked our authors to explore the dynamics of official responses to the crisis at hand. What was the response, if any? Who, if anyone, took ownership? What might explain these dynamics?

\subsection{ImPlicATIONS FOR PRACTITIONERS}

Our research on creeping crisis is not just an academic exercise. Many of society's current ills bear the hallmarks of creeping crises and cast into question governments' readiness to manage them. In some respects, creeping crises magnify the challenges traditionally associated with managing crises (Boin et al., 2016). In other respects, these kinds of crises demand new thinking about how they should be dealt with.

Traditional crisis management challenges for practitioners include the detection challenge. How can societies improve their ability to "see" a crisis emerging, and what tools are fit for that purpose? Early warning and anticipatory governance are popular themes in the academic literature. But for practitioners the challenges are myriad. Few emerging crises resemble their forebearers, making it difficult to know what to look for (crisis emergence is easy to see only in retrospect). Creeping crises add a 
new wrinkle to the detection challenge. Long incubation periods offer opportunities to detect their emergence, if we know where to look. But the complicated nature of that incubation-intertwined with human and ecological systems, evolving over time and space-make detection exceedingly difficult. "Horizon scanning" for creeping crises requires a different and perhaps rare sort of expertise, which reaches across a wider segment of government and society than traditional crises demand.

Detection is less a problem for the creeping crises that are already with us. The challenge then becomes one of preventive intervention rather than detection. Long incubation periods offer plenty of opportunities for governments to act, foreboding massive criticism about accountability if creeping crises turn into a major, destructive event. But intervening too early may be counterproductive. Growing problems can dissipate on their own accord. Implementation of draconian measures while the consequences of the crisis are still uncertain leads to public outcries and a loss of governmental legitimacy. Moreover, who should intervene and how? Acting on a crisis establishes ownership, too, which risk-averse governments may wish to avoid.

Creeping crises also introduce specific management challenges for practitioners. First, creeping crises signal their existence through precursor events long before "the big one," leading to questions of who should act and when. A single event can be managed, even successfully, by skilled crisis managers. But those crisis managers are likely to see the deeper problem continuing to evolve at the same time as politicians are ready to move on. Finding a longer-term, sustainable response may be the real challenge here. Second, an adequate response is complicated by the sheer breadth of societal actors required to act. Many of the creeping crises outlined in this book cannot be dealt with by formal crisis managers alone. They require a mix of experts, technicians, private sector actors, NGOs, even diplomats to fully understand how crises evolve (often far away and over time) and how they are best addressed (in the here and now).

Third, and perhaps most critical for practitioners, is the fact that managing creeping crises requires societal sacrifice. As demonstrated in this book, many creeping crises accumulate within the essential arteries that power our societies. From food supply systems to information technology, and from energy grids to social media and travel networks, we depend on the systems that bring efficiency and choice-but also dangers. Addressing those dangers requires sacrificing what we enjoy in the short term for longer term societal sustainability. Perrow (1984), mentioned above, spoke of 
the need to "decouple" systems to avoid crisis escalation-an insight with renewed relevance in an age of deeply ingrained creeping crises. Few politicians, or the industries that profit from these systems, are likely to jump at the opportunity to restrict them.

In the case of creeping crises, the legitimacy of public institutions and political leaders is cast into sharp relief. Today, people worry not if but when global warming, migration, remaining foreign fighters, disruptive technologies, market disequilibrium, or income inequality will cause a major crisis. As the nature of the creeping crisis is not widely agreed upon, the very act of branding it as a crisis (or not) will affect the reaction to that threat. It is easy to imagine how a botched meaning-making process may undermine the legitimacy of leaders, which will undermine the effectiveness of the response. This, in turn, may further undermine legitimacy, prompting a vicious circle.

\subsection{Outline of This Book}

Our goal in this book is to explore and develop further the creeping crisis concept. The chapters delve into specific cases to evaluate the utility of the framework as well as illuminating the case in greater color and detail. As societies grapple with problems that resemble the creeping crisis, improving our understanding of their key dynamics also increases the changes of acting upon them effectively.

Chapter 2, by Alina Engström, studies the scourge of antimicrobial resistance. She finds that the long incubation of this crisis typifies the time and space dimension of the creeping crisis notion. Attention peaks occasionally, but not always in the immediate aftermath of precursor events. Responses to the problem are hampered by a lack of ownership. Chapter 3 explores the "WannaCry" cyber crisis. Maria Foteini Prevezianou confirms the difficulty of detecting this kind of event, even when the signals are clear. The question arises from this chapter of whether WannaCry was a creeping crisis in itself, or a sign of a wider crisis to come. Chapter 4 takes up the issue of remaining foreign fighters-individuals who left their home countries to travel to war zones, and who are now barred from returning. Yrsa Landström shows how these fighters sit in refugee camps in which a broader humanitarian crisis—or even a radicalization process - can be incubated. By not bringing the foreign fighters home, governments can sustain the threat of increasing radicalization and terrorist attacks. 
In Chap. 5, Swapnil Vashishtha and Mark Rhinard study the phenomenon of Big Data. Here, the creeping crisis perspective starkly reveals the accumulating nature of the problem, the occasional precursor events, and the acceptance by some actors that a major crisis is on the horizon. Still, the authors show that societal dependence and vested interests hamper what would be a costly intervention. Chapter 6 contains the case of the European border crisis of 2015. Yrsa Landström and Magnus Ekengren consider the movement of migrants across the continent as hardly a surprise. Many previous indicators suggested an impending humanitarian catastrophe. Focused on the Sweden's response, the authors show the government delayed reacting largely because of ideological blinders that impaired debate about when to prepare.

Chapter 7 is comparative. Alina Engström, Marte Luesink, and Arjen Boin compare Dutch and Swedish responses to the coronavirus outbreak, finding key similarities but also differences that help to explain the delayed response. Chapter 8, by Elin Jakobsson turns to the question of climate change-induced migration. This simmering problem has long held the promise of a full outbreak, but only precursor events attract attention. Those events are treated as disasters, partially addressed, and then abandoned-allowing the problem to continue growing. Chapter 9 offers the last case. Alexander Verdoes and Arjen Boin examine the emergence of earthquakes in parts of the Netherlands, which are clear signs of how gas fields are exploited. Authorities ignored the signals, thus sustaining the problem, and the problem has now led to a major loss in the legitimacy of public institutions.

Our conclusion summarizes the key findings of the book and sets a research agenda for the further study of creeping crisis.

\section{REFERENCES}

't Hart, P. (1993). Symbols, rituals and power: The lost dimensions of crisis management. Journal of Contingencies and Crisis Management, 1(1), 36-50.

't Hart, P., \& Boin, R. A. (2001). Between crisis and normalcy: The long shadow of post-crisis politics. In U. Rosenthal, R. A. Boin, \& L. K. Comfort (Eds.), Managing crisis: Threats, dilemmas, opportunities (pp. 28-46). Springfield: Charles C. Thomas.

Ansell, C., \& Bartenberger, M. (2017). Unruly problems. In C. Ansell, J. Trondal, \& M. Ogard (Eds.), Governance in turbulent times. Oxford: Oxford University Press. 
Baumgartner, F. R., \& Jones, B. D. (1993). Agendas and instability in American politics. Chicago, IL: University of Chicago Press.

Boin, A., 't Hart, P., Stern, E., \& Sundelius, B. (2016). The politics of crisis management. Cambridge University Press.

Boin, A., Brown, C., \& Richardson, J. (2019). Managing Hurricane Katrina: Lessons from a megacrisis. Baton Rouge: LSU Press.

Boin, A., Ekengren, M., \& Rhinard, M. (2020). Hiding in plain sight: Conceptualizing the creeping crisis. Risk, Hazards \& Crisis in Public Policy, 11(2), 116-138. https://doi.org/10.1002/rhc3.12193

Boin, A., \& Lodge, M. (2019). The new twilight zone between crisis and risk management. Risk and Regulation, Spring, LSE CARR Newsletter.

Boin, A., McConnell, A., \& 't Hart, P. (Eds.) (2008). Governing after crisis: The politics of investigation, accountability and learning. Cambridge: Cambridge University Press.

Buchanan, M. (2000). Ubiquity: Why catastrophes happen. New York: Three Rivers Press.

Buzan, B., Waever, O., \& de Wilde, J. (1998). Security: A new framework for analysis. London: Lynne Rienner.

Downs, A. (1972). Up and down with ecology-the "issue attention" cycle. Public Interest, 28, 38-50.

Hood, C. (2011). The blame game: Spin, bureaucracy and self-preservation in government. Princeton, NJ: Princeton University Press.

Jones, E., Kelemen, R. D., \& Meunier, S. (2016). Failing forward? The Euro crisis and the incomplete nature of European integration. Comparative Political Studies, 49(7), 1010-1034. https://doi.org/10.1177/0010414015617966

Kahneman, D. (2013). Thinking, fast and slow. New York: Farrar, Straus and Giroux.

Kingdon, J. W. (1995). Agendas, alternatives, and public policies. Upper Saddle River, NJ: Pearson.

La Porte, T. R. (1975). Complexity and uncertainty: A challenge to action. In T. R. La Porte (Ed.), Organized social complexity: Challenge to politics and policy (pp. 332-356). Princeton, NJ: Princeton University Press.

McLaughlin, P., \& Dietz, T. (2008). Structure, agency and environment: Toward an integrated perspective on vulnerability. Global Environmental Change, $18(1), 99-111$.

Perrow, C. (1984). Normal accidents: Living with high-risk technologies. New York: Basic Books.

Rittel, H. W. J., \& Webber, M. M. (1973). Dilemmas in a general theory of planning. Policy Sciences, 4(2), 155-169. https://doi.org/10.1007/BF01405730

Rosenthal, U., Charles, M. T., \& 't Hart, P. (Eds.) (1989). Coping with crises: The management of disasters, riots and terrorism. Springfield: Charles C. Thomas. 
Schattschneider, E. E. (1960). The semisovereign people: A realist's view of democracy in America. Hinsdale: Dryden Press.

Scheffer, M. (2009). Critical transitions in nature and society. Princeton, NJ: Princeton University Press.

Schön, D. A., \& Rein, M. (1994). Frame reflection: Toward the resolution of intractable policy controversies. New York: Basic Books.

Seabrooke, L., \& Tsingou, E. (2019). Europe's fast- and slow-burning crises. Journal of European Public Policy, 26(3), 468-481. https://doi.org/10.108 0/13501763.2018.1446456

Shrivastava, P., Mitroff, I. I., Miller, D., \& Miglani, A. (1988). Understanding industrial crises. Journal of Management Studies, 25(4), 285.

Smet, H., Lagadec, P., \& Leysen, J. (2012). Disasters out of the box: A new ballgame? Journal of Contingencies and Crisis Management, 20(3), 138-148. https://doi.org/10.1111/j.1468-5973.2012.00666.x

Taylor, M. (2001). The moment of complexity. Chicago, IL: University of Chicago Press.

Turner, B. A. (1978). Man-made disasters. London: Wykeham.

Open Access This chapter is licensed under the terms of the Creative Commons Attribution 4.0 International License (http://creativecommons.org/licenses/ by $/ 4.0 /)$, which permits use, sharing, adaptation, distribution and reproduction in any medium or format, as long as you give appropriate credit to the original author(s) and the source, provide a link to the Creative Commons licence and indicate if changes were made.

The images or other third party material in this chapter are included in the chapter's Creative Commons licence, unless indicated otherwise in a credit line to the material. If material is not included in the chapter's Creative Commons licence and your intended use is not permitted by statutory regulation or exceeds the permitted use, you will need to obtain permission directly from the copyright holder.

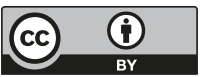

